\title{
Partial response to imatinib treatment in a patient with unresectable gastrointestinal stromal tumor: A case report and mini literature review
}

\author{
XIAOLONG WU, LIBO FENG, QING LIU, DONG XIA and LIANG XU \\ Department of Gastrointestinal Surgery, The Affiliated Hospital of Luzhou Medical College, \\ Luzhou, Sichuan 646000, P.R. China
}

Received February 24, 2015; Accepted April 26, 2016

DOI: $10.3892 / e t m .2016 .3614$

\begin{abstract}
The aim of the present study was to evaluate the efficacy and safety of imatinib mesylate in unresectable gastrointestinal stromal tumor (GIST) and to discuss its therapeutic regimen. A patient with unresectable GIST is described, and several key clinical studies are reviewed, including the clinical trials B2222 and S0033, which contain recently reported results of the long-term clinical outcome of imatinib in patients with unresectable or metastatic GIST. The recent results of the two studies demonstrate the long-term efficacy and safety of imatinib for unresectable or metastatic GIST. A positive response to imatinib treatment was observed in the present patient, which is consistent with the data of the B2222 and S0033 trials. However, further long-term, large-scale, multicenter and controlled trials are required to determine the relative efficacy of combining imatinib agents with surgical procedures or administering imatinib alone.
\end{abstract}

\section{Introduction}

Gastrointestinal stromal tumor (GIST) is the most common mesenchymal neoplasm of the digestive tract (1). In the pre-imatinib era, surgical resection was the only effective treatment for GISTs. The 5-year survival rate for patients with GISTs ranges from $28-80 \%$; however, tumor progression occurs in $\sim 50 \%$ of patients, even following complete resection (2). Imatinib mesylate, a tyrosine kinase inhibitor, has been the standard first-line pharmacological therapy for unresectable and/or metastatic GIST since it was approved, and significantly improves the overall survival rate (3). The present study reports the case of a patient with GIST in the

Correspondence to: Professor Dong Xia, Department of Gastrointestinal Surgery, The Affiliated Hospital of Luzhou Medical College, 25 Taiping Street, Luzhou, Sichuan 646000, P.R. China E-mail:xdcndoc@126.com

Key words: gastrointestinal stromal tumor, unresectable, imatinib, literature review
Affiliated Hospital of Luzhou Medical College (Luzhou, China), and presents a review of the pertinent literature. The purpose was to assess the efficacy and safety of imatinib mesylate in the treatment of unresectable GIST and to discuss the optimal therapeutic plan for unresectable GIST.

\section{Case report}

A 57-year-old woman was admitted to the Department of Gastrointestinal Surgery of the Affiliated Hospital of Luzhou Medical College on March 25, 2013, complaining of pain in the left upper abdomen for 10 days and aggravation for 2 days. A computed tomography (CT)-scan showed a large mass in the left upper abdomen (Fig. 1A), and upper gastrointestinal tract CT enterography revealed a mass in the left upper abdominal cavity. In addition, the lower part of the esophagus and the fundus of the stomach were shifted, and the stomach appeared irregular. A hard, irregular-shaped tumor outside of the cavity, $\sim 14 \times 15 \times 15 \mathrm{~cm}$ in size, which was closely connected with the diaphragmatic muscle, pancreas, spleen and relevant blood vessels, was identified during an exploratory laparotomy. A tumor biopsy $(\sim 1.5 \mathrm{~cm})$ was performed without resection of the tumor. A pathological analysis performed by two experienced pathologists showed GIST and a mitotic index of $>5$ mitoses per 50 high-power fields. Immunohistochemical analyses were positive for CD117 (rabbit anti-CD117 polyclonal antibody; cat. no. A4502; 1:200 dilution; Dako, Glostrup, Denmark), CD34 (mouse anti-CD34 monoclonal antibody; cat. no. M7165; 1:400 dilution; Dako) and Ki67 (mouse anti-Ki67 monoclonal antibody; cat. no. M7204; 1:100 dilution; Dako), and negative for Dog1 (rabbit anti-Dog1 monoclonal antibody; cat. no. RM-9132-R7; 1:200 dilution; Thermo Fisher Scientific, Inc., Waltham, MA, USA), S-100 (rabbit anti-S-100 polyclonal antibody; cat. no. Z0311; 1:300 dilution; Dako), smooth muscle actin (mouse anti-SMA monoclonal antibody; cat. no. M0851; 1:150 dilution; Dako) and P53 (mouse anti-P53 monoclonal antibody; cat. no. M7001; 1:150 dilution; Dako). The diagnosis of a high-grade non-metastatic GIST was thus confirmed. Treatment of the patient was initiated with oral administration of $400 \mathrm{mg}$ imatinib (Novartis Pharma Stein AG, Stein, Switzerland) daily, without tumor gene detection, and the patient was reviewed by abdominal CT scans every 

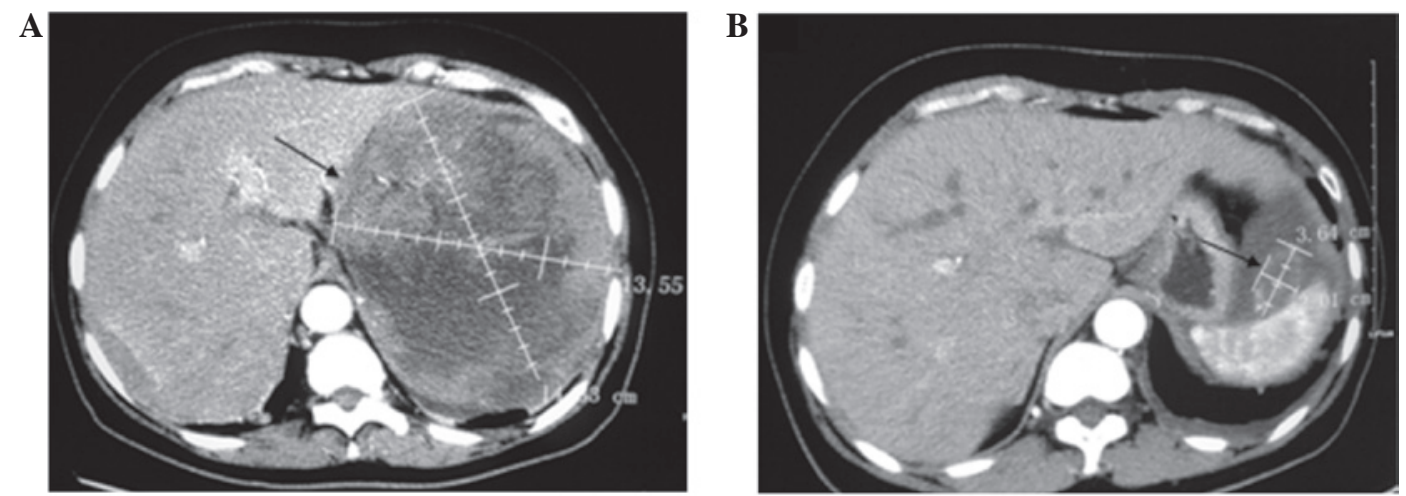

Figure 1. Transaxial computed tomography scans showing (A) a large mass in the left upper abdomen and (B) a marked reduction in the size of the mass after 11 months of treatment with imatinib.

three months. During the drug therapy period, the patient experienced mild adverse effects, including nausea, diarrhea, edema and leucopenia; however, these were normalized following symptomatic treatment. In March 7, 2014, a CT scan (Fig. 1B) showed that the mass was reduced in size. However, the patient refused to undergo surgery and persisted with agent therapy. At the 16-month follow-up, the mass had decreased markedly, without tumor progression and metastasis. The patient had achieved a partial response and had tolerated the treatment well. This study was conducted in accordance with the Declaration of Helsinki and with approval from the Ethics Committee of Luzhou Medical College. Written informed consent was obtained from the patient prior to the study.

\section{Discussion}

GISTs are the most common type of mesenchymal neoplasm of the digestive tract (1). GISTs most commonly arise in the stomach $(60 \%)$, although they may also occur in the small intestine (25\%), rectum (5\%) and other sites along the GI tract, including the esophagus, colon, appendix and gallbladder (4). These so-called extra-intestinal GISTs may occupy the mesentery or omentum (5). GISTs originate from interstitial cells of Cajal and related stem cells, which express c-Kit, CD117 and CD34. The majority of GISTs have oncogenic mutations in either receptor tyrosine kinase genes (KIT) or platelet-derived growth factor receptor- $\alpha$ (PDGFR $\alpha$ ), resulting in the activation of intracellular signaling pathways and the deregulation of cellular proliferation and apoptosis inhibition (6). The mutation frequencies in exons 11 and 9 of the KIT gene are 67 and $8 \%$, respectively. Exons 13 and 17 rarely exhibit these mutations, while exons 18 and 12 show lower mutation rates for PDGFR $\alpha$ of 5 and 1\%, respectively (5). The clinical manifestations of GISTs are highly variable and depend on tumour location, size and growth pattern (7). The most common presenting symptoms are associated with gastrointestinal bleeding, including melena, hematemesis or symptomatic anaemia, while other symptoms may include abdominal fullness, early satiety and a palpable mass or pain (7). Among patients with GIST, $15-50 \%$ present with overt metastasis, and the most common sites of metastases are the peritoneum and liver (8). Metastasis of GIST to the lungs, bones and brain is rare (9). Diagnosis of GIST can be made using a combination of abdominal CT scans, endoscopic ultrasonography, pathological immunohistochemical analyses and/or genetic detection.

Imatinib mesylate is a potent and select inhibitor of the protein tyrosine kinase Bcr-Abl, PDGFR $\alpha$ and KIT (10). Imatinib exerts its therapeutic effect in chronic myeloid leukemia (CML) via competitive inhibition at the adenosine triphosphate binding site of Bcr-Abl tyrosine of proteins involved in Bcr-Abl signal transduction (11). In GIST, imatinib interrupts KIT-mediated signal transduction by a mechanism of action similar to its inhibition of Bcr-Abl tyrosine kinase in CML patients (11). Prior to the advent of imatinib therapy, the median survival period was 19 months in patients with metastatic GIST and 12 months in those with unresectable GIST (12). Imatinib has demonstrated clinical benefit for both patient groups; improving progression-free survival (PFS) and overall survival (OS) rates in numerous clinical trials (13-17). Accordingly, imatinib is currently approved as the first-line option for the treatment of unresectable GISTs.

The clinical studies B2222 and S0033 were reviewed in the present study, with particular emphasis on the recently reported results of the long-term clinical outcome of imatinib for unresectable GIST. The results from the two studies (Tables I and II) (13-17) indicate that imatinib achieves long-term tumor control and remains well tolerated over long-term administration.

The studies are open-label, multicenter trial, double-blinded and random trials, with a maximum follow-up time of 10 years for patients with unresectable GIST. The results of the S0033 are consistent with the long-term efficacy and safety of imatinib that was observed in B2222. During the median follow-up of 5 years, the results of both studies showed a similar median PFS of $\sim 20$ months and median OS of $\sim 56$ months. Long-term data from the two clinical trials also reveal that certain patients remain alive after long-term imatinib treatment, including $35 \%$ at 9 years in the B2222 study and $31 \%$ at 8 years in the S0033 study (Table I). Imatinib has been suggested to be suitable for long-term administration due to its favorable safety profile. Indeed, no major toxicities were noted in patients who were treated with imatinib for $\sim 10$ years in the B2222 and S0033 studies $(14,17)$, and the majority of imatinib-associated adverse events are minor (Table II). Collectively, the results from the phase II B2222 and phase III S0033 trials suggest that imatinib achieves long-term tumor control in a significant proportion of patients with unresectable GIST for periods approaching 10 years. 
Table I. Efficacy reported by imatinib trials for unresectable gastrointestinal stromal tumor.

\begin{tabular}{|c|c|c|}
\hline Study parameter & $\begin{array}{l}\text { Phase II US-Finland } \\
\text { study B2222 (13-15) }\end{array}$ & $\begin{array}{l}\text { Phase III North American } \\
\text { intergroup study S0033 }(16,17)\end{array}$ \\
\hline \multicolumn{3}{|l|}{ Patients } \\
\hline Number & 147 & 694 \\
\hline Grouping & Randomized, 400 or 600 mg/day & $\begin{array}{l}\text { Randomized, } 400 \mathrm{mg} / \text { day }(\operatorname{arm~A}) \\
\text { or } 800 \mathrm{mg} / \text { day }(\operatorname{arm~B})\end{array}$ \\
\hline \multicolumn{3}{|l|}{ Overall response rate } \\
\hline Follow-up period & 63 months & 4.5 years \\
\hline Median response rate $(\%)$ & 68.1 & 45 \\
\hline Arms/treatment & Similar between arms & Similar between arms \\
\hline \multicolumn{3}{|l|}{ Median PFS } \\
\hline Follow-up period & $\begin{array}{l}\text { 63-month median follow-up: } \\
24 \text { months } \\
9.4 \text {-year median follow-up: } \\
\text { Estimated time to progression rate } \\
\text { for all patients was } 14 \%\end{array}$ & $\begin{array}{l}\text { Median follow-up of } 4.5 \text { years: } \\
18 \text { months for arm A } \\
20 \text { months for arm B }\end{array}$ \\
\hline \multicolumn{3}{|l|}{ Median OS } \\
\hline & $\begin{array}{l}63 \text {-month median follow-up: } \\
57 \text { months } \\
\text { 9.4-year median follow-up: Estimated } \\
\text { OS rate for all patients was } 35 \% \\
38 \% \text { for patients with CR/PR } \\
49 \% \text { for patients with SD } \\
0 \% \text { for patients with PD }\end{array}$ & $\begin{array}{l}\text { Median follow-up of } 4.5 \text { years: } \\
55 \text { months for arm A } \\
51 \text { months for arm B } \\
\text { Median follow-up of } 8.8 \text { years: } \\
136 \text { patients alive } \\
\text { Estimated OS: } \\
8 \text { years: } 31 \% \\
9 \text { years: } 26 \% \\
10 \text { years: } 21 \%\end{array}$ \\
\hline
\end{tabular}

PFS, progression-free survival; OS, overall survival; CR, complete response; PR, partial response; SD, stable disease; PD, progressive disease.

Table II. Safety results of imatinib trials for unresectable gastrointestinal stromal tumor.

\begin{tabular}{|c|c|c|}
\hline Study parameter & $\begin{array}{l}\text { Phase II US-Finland } \\
\text { study B2222 (13-15) }\end{array}$ & $\begin{array}{l}\text { Phase III North American } \\
\text { intergroup study S0033 }(16,17)\end{array}$ \\
\hline $\begin{array}{l}\text { Common adverse } \\
\text { events }\end{array}$ & $\begin{array}{l}\text { Edema, nausea, fatigue, diarrhea, } \\
\text { myalgia, dermatitis, headache, } \\
\text { abdominal pain }\end{array}$ & Edema, nausea, fatigue, rash, pain \\
\hline $\begin{array}{l}\text { Mild or moderate } \\
\text { adverse events } \\
(\text { grade } 1 \text { or } 2)^{*}\end{array}$ & $\begin{array}{l}\text { The majority of the common } \\
\text { adverse events were mild or } \\
\text { moderate }\end{array}$ & $\begin{array}{l}\text { The majority of the common adverse } \\
\text { events were mild or moderate, } \\
\text { particularly for arm A patients }\end{array}$ \\
\hline $\begin{array}{l}\text { Serious adverse } \\
\text { events (grades } 3-5)^{*}\end{array}$ & $\begin{array}{l}\text { Grade } 3 \text { or } 4 \text { events occurred } \\
\text { in } 21.1 \% \text { of patients. }\end{array}$ & $\begin{array}{l}\text { Grade } 3-5 \text { events occurred in } 43 \% \text { of } \\
\text { arm A patients and } 63 \% \text { of arm B. } \\
\text { Two lose-dose patients (1\%) and nine } \\
\text { high-dose patients ( } 3 \% \text { ) underwent } \\
\text { possible treatment-associated } \\
\text { mortality. }\end{array}$ \\
\hline
\end{tabular}

*Adverse effects were graded according to: http://ctep.cancer.gov/protocolDevelopment/electronic_applications/docs/ctcmanual_v4_10-4-99.pdf.

There are numerous factors that affect the response of GIST to imatinib therapy, including kinase genotype mutation, hemoglobin, albumin level, primary tumor site and metastasis location; however, KIT mutation is one of the most important factors (18). Corless and Heinrich (18) reported correlations between tumor genotype and objective 
response (complete and partial) in a review of four trials. The objective response rates for patients with mutations in exons 11 or 9 of KIT, or with wild-type GISTs, are 72, 38 and $28 \%$, respectively. Likewise, the probabilities of primary resistance to imatinib for patients with mutations in exons 11 or 9 of KIT, or with wild-type GISTs, are 5, 16 and $23 \%$, respectively. Secondary resistance to imatinib increases with the duration of drug treatment; however, the mechanism underlying this resistance is unclear. It is widely speculated that this phenomenon is associated with secondary KIT mutations (18). Tumors with an underlying primary KIT mutation in exon 11 exhibit improved response rates compared with other mutational subtypes, but are at higher risk of developing secondary mutations than those with an KIT exon 9 mutation or wild-type GISTs (19).

A previous review (20) concluded that neoadjuvant imatinib should be administered to reduce tumor bulk and thus facilitate the complete surgical resection or increase the likelihood of organ preservation of initially unresectable or borderline resectable GISTs. As the first-line treatment for unresectable GISTs, certain reports (21) have suggested imatinib interruption is associated with a major risk of rapid progression. Thus, imatinib administration should be continued until disease progression or intolerance to toxicity in patients in whom disease control has been achieved. The initial dose is usually $400 \mathrm{mg} /$ day; however, it may be increased to $600 \mathrm{mg} /$ day in patients with KIT exon 9 mutations. Surgical removal of the lesion may be performed and postoperative imatinib dose should increase when local progression emerged after excluding patient compliance $(22,23)$. In cases of widespread progression, imatinib dose may be increased to $600 \mathrm{mg} / \mathrm{day}$, which may be more appropriate for Chinese patients (24), or the second-line sunitinib may alternatively be administered. If patients show no response to imatinib or sunitinib, regorafenib is recommended as the third-line therapy (25). A prospective, randomized, double-blind trial (26) revealed that certain patients with GIST may retain sensitivity to certain tyrosin-kinase inhibitors following the failure of all approved inhibitors. Thus, the reintroduction of tyrosine-kinase inhibitors may delay disease progression.

During surgery in the present case, the tumor was found to be closely connected with the diaphragmatic muscle, pancreas, spleen and relevant blood vessels, and was therefore identified as a case of unresectable GIST. Without tumor gene detection, the patient initially received the standard $400 \mathrm{mg} /$ day dose of imatinib. At the 16-month follow-up, the patient achieved a partial response, with an abdominal $\mathrm{CT}$ scan showing a significant reduction of the tumor size $(\sim 70 \%)$. During the treatment period, the patient experienced mild side effects, including nausea, diarrhea, edema and leucopenia; however, these symptoms became normal following symptomatic treatment. Thus, the present case conforms with the good efficacy and safety of imatinib in GIST reported in the aforementioned literature. According to the proposal in a previous review (20), surgery may be considered a viable option for patients with stable disease following imatinib therapy. However, the patient refused to undergo resection of the lesion after the tumor volume was reduced and ultimately received imatinib therapy alone. Two clinical studies, B2222 and S0033, demonstrated that long-term imatinib use increased the 9-year OS rate in patients with unresectable GIST by 35 and $26 \%$, respectively, and that side effects were relatively rare. Prior studies $(2,27)$ have suggested that patients with advanced GIST exhibiting stable disease or limited progression while receiving kinase inhibitor therapy exhibit prolonged PFS and OS following debulking surgery. However, these were small-scale and short-term clinical trials with no prominent clinical value. Therefore, when patients with unresectable GISTs have obtained stable disease or limited progression after receiving imatinib therapy, it remains unclear whether a combination of imatinib with surgical resection is more beneficial than receiving imatinib alone. Thus, further long-term, large-scale, multicenter, controlled trials are required to elucidate this unknown.

\section{References}

1. Søreide K, Sandvik OM, Søreide JA, Giljaca V, Jureckova A and Bulusu VR: Global epidemiology of gastrointestinal stromal tumours (GIST): A systematic review of population-based cohort studies. Cancer Epidemiol 40: 39-46, 2016.

2. Du CY, Zhou Y, Song C, Wang YP, Jie ZG, He YL, Liang XB, Cao H, Yan ZS and Shi YQ: Is there a role of surgery in patients with recurrent or metastatic gastrointestinal stromal tumours responding to imatinib: A prospective randomised trial in China. Eur J Cancer 50: 1772-1778, 2014.

3. ESMO/European Sarcoma Network Working Group: Gastrointestinal stromal tumours: ESMO Clinical Practice Guidelines for diagnosis, treatment and follow-up. Ann Oncol 25 (Suppl 3): iii21-iii26, 2014.

4. Corless CL, Fletcher JA and Heinrich MC: Biology of gastrointestinal stromal tumors. J Clin Oncol 22: 3813-3825, 2004.

5. Barnett CM, Corless CL and Heinrich MC: Gastrointestinal stromal tumors: Molecular markers and genetic subtypes. Hematol Oncol Clin North Am 27: 871-888, 2013.

6. Corless CL, Barnett CM and Heinrich MC: Gastrointestinal stromal tumours: Origin and molecular oncology. Nat Rev Cancer 11: 865-878, 2011.

7. Iorio N, Sawaya RA and Friedenberg FK: Review article: The biology, diagnosis and management of gastrointestinal stromal tumours. Aliment Pharmacol Ther 39: 1376-1386, 2014.

8. Joensuu H, Fletcher C, Dimitrijevic S, Silberman S, Roberts P and Demetri G: Management of malignant gastrointestinal stromal tumors. Lancet Oncol 3: 655-664, 2002.

9. Miettinen M, Furlong M, Sarlomo-Rikala M, Burke A, Sobin LH and Lasota J: Gastrointestinal stromal tumors, intramural leiomyomas, and leiomyosarcomas in the rectum and anus: A clinicopathologic, immunohistochemical, and molecular genetic study of 144 cases. Am J Surg Pathol 25: 1121-1133, 2001.

10. Day E, Waters B, Spiegel K, Alnadaf T, Manley PW, Buchdunger $\mathrm{E}$, Walker $\mathrm{C}$ and Jarai G: Inhibition of collagen-induced discoidin domain receptor 1 and 2 activation by imatinib, nilotinib and dasatinib. Eur J Pharmacol 599: 44-53, 2008.

11. Peng B, Lloyd P and Schran H: Clinical pharmacokinetics of imatinib. Clin Pharmacokinet 44: 879-894, 2005.

12. DeMatteo RP, Lewis JJ, Leung D, Mudan SS, Woodruff JM and Brennan MF: Two hundred gastrointestinal stromal tumors: Recurrence patterns and prognostic factors for survival. Ann Surg 231: 51-58, 2000

13. Blanke CD, Demetri GD, von Mehren M, Heinrich MC, Eisenberg B, Fletcher JA, Corless CL, Fletcher CD, Roberts PJ, Heinz D, et al: Long-term results from a randomized phase II trial of standard-versus higher-dose imatinib mesylate for patients with unresectable or metastatic gastrointestinal stromal tumors expressing KIT. J Clin Oncol 26: 620-625, 2008.

14. von Mehren M, Heinrich MC, Joensuu H, Blanke CD, Wehrle E and Demetri GD: Follow-up results after 9 years (yrs) of the ongoing, phase II B2222 trial of imatinib mesylate (IM) in patients (pts) with metastatic or unresectable KIT+ gastrointestinal stromal tumors (GIST). J Clin Oncol 29 (Suppl): Abstract 10016, 2011.

15. Demetri GD, von Mehren M, Blanke CD, Van den Abbeele AD, Eisenberg B, Roberts PJ, Heinrich MC, Tuveson DA, Singer S, Janicek M, et al: Efficacy and safety of imatinib mesylate in advanced gastrointestinal stromal tumors. N Engl J Med 347: 472-480, 2002 . 
16. Blanke CD, Rankin C, Demetri GD, Ryan CW, von Mehren M, Benjamin RS, Raymond AK, Bramwell VH, Baker LH, Maki RG, et al: Phase III randomized, intergroup trial assessing imatinib mesylate at two dose levels in patients with unresectable or metastatic gastrointestinal stromal tumors expressing the kit receptor tyrosine kinase: S0033. J Clin Oncol 26: 626-632, 2008.

17. Blanke CD, Rankin C, Benjamin R, Raymond AK, Heinrich MC Fletcher CDM, Crowley J, Borden EC, Demetri GD and Baker LH: Long-term survival on S0033-a phase III randomized, intergroup trial assessing imatinib mesylate at two dose levels in patients with unresectable or metastatic gastrointestinal stromal tumors (GISTs). Eur J Cancer 47 (Suppl 1): Abstract 9404, 2011.

18. Corless CL and Heinrich MC: Molecular pathobiology of gastrointestinal stromal sarcomas. Annu Rev Pathol 3: 557-586, 2008.

19. Wardelmann E, Merkelbach-Bruse S, Pauls K, Thomas N, Schildhaus HU, Heinicke T, Speidel N, Pietsch T, Buettner R, Pink D, et al: Polyclonal evolution of multiple secondary KIT mutations in gastrointestinal stromal tumors under treatment with imatinib mesylate. Clin Cancer Res 12: 1743-1749, 2006.

20. Serrano $C$ and George $S$ : Recent advances in the treatment of gastrointestinal stromal tumors. Ther Adv Med Oncol 6: 115-127, 2014.

21. Patrikidou A, Chabaud S, Ray-Coquard I, Bui BN, Adenis A, Rios M, Bertucci F, Duffaud F, Chevreau C, Cupissol D, et al French Sarcoma Group: Influence of imatinib interruption and rechallenge on the residual disease in patients with advanced GIST: Results of the BFR14 prospective French Sarcoma Group randomised, phase III trial. Ann Oncol 24: 1087-1093, 2013.
22. Blay JY and Rutkowski P: Adherence to imatinib therapy in patients with gastrointestinal stromal tumors. Cancer Treat Rev 40: 242-247, 2014.

23. Patel S: Managing progressive disease in patients with GIST: Factors to consider besides acquired secondary tyrosine kinase inhibitor resistance. Cancer Treat Rev 38: 467-472, 2012.

24. Li J, Gong JF, Li J, Gao J, Sun NP and Shen L: Efficacy of imatinib dose escalation in Chinese gastrointestinal stromal tumor patients. World J Gastroenterol 18: 698-703, 2012.

25. Demetri GD, Reichardt P, Kang YK, Blay JY, Rutkowski P, Gelderblom H, Hohenberger P, Leahy M, von Mehren M, Joensuu $\mathrm{H}$, et al: Efficacy and safety of regorafenib for advanced gastrointestinal stromal tumors after failure of imatinib and sunitinib (GRID): An international, multicentre, randomised, placebo-controlled, phase 3 trial. Lancet 381: 295-302, 2013.

26. Kang YK, Ryu MH, Yoo C, Ryoo BY, Kim HJ, Lee JJ, Nam BH, Ramaiya N, Jagannathan J and Demetri GD: Resumption of imatinib to control metastatic or unresectable gastrointestinal stromal tumours after failure of imatinib and sunitinib (RIGHT): A randomised, placebo-controlled, phase 3 trial. Lancet Oncol 14: 1175-1182, 2013.

27. Park SJ, Ryu MH, Ryoo BY, Park YS, Sohn BS, Kim HJ, Kim CW, $\mathrm{Kim} \mathrm{KH}, \mathrm{Yu} \mathrm{CS}$, Yook JH, et al: The role of surgical resection following imatinib treatment in patients with recurrent or metastatic gastrointestinal stromal tumors: Results of propensity score analyses. Ann Surg Oncol 21: 4211-4217, 2014. 